\title{
Metallomacrocycles Incorporating a Hemilabile Tröger's Base Derived Ligand
}

Meisa S. Khoshbin ${ }^{\dagger}$ Maxim V. Ovchinnikov, ${ }^{\dagger}$ Chad A. Mirkin, ${ }^{\dagger *}$ James A. Golen,${ }^{\dagger}$ and Arnold L. Rheingold

$\dagger$ Department of Chemistry and Institute for Nanotechnology, 2145 Sheridan Road, Northwestern University, Evanston, Illinois 60208, and the $\$$ Department of Chemistry and Biochemistry, University of California, San Diego, La Jolla, CA 92093.

Email: chadnano@northwestern.edu

\section{Supporting Information}

Figure S1. Analytical GPC traces of (A) closed $\mathrm{Cu}(\mathrm{I})$ complex, 5, and open $\mathrm{Cu}(\mathrm{I})$ complex, 8, (B) mixture of closed Rh(I)complexes, $\mathbf{6}$ and 7, and open Rh(I) complexes, 9 - 11.

A
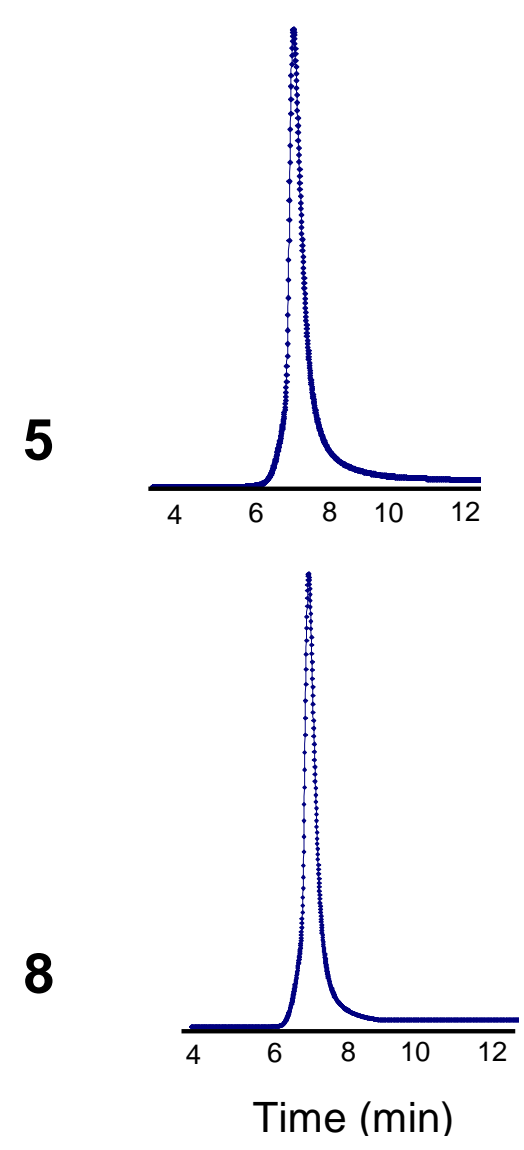

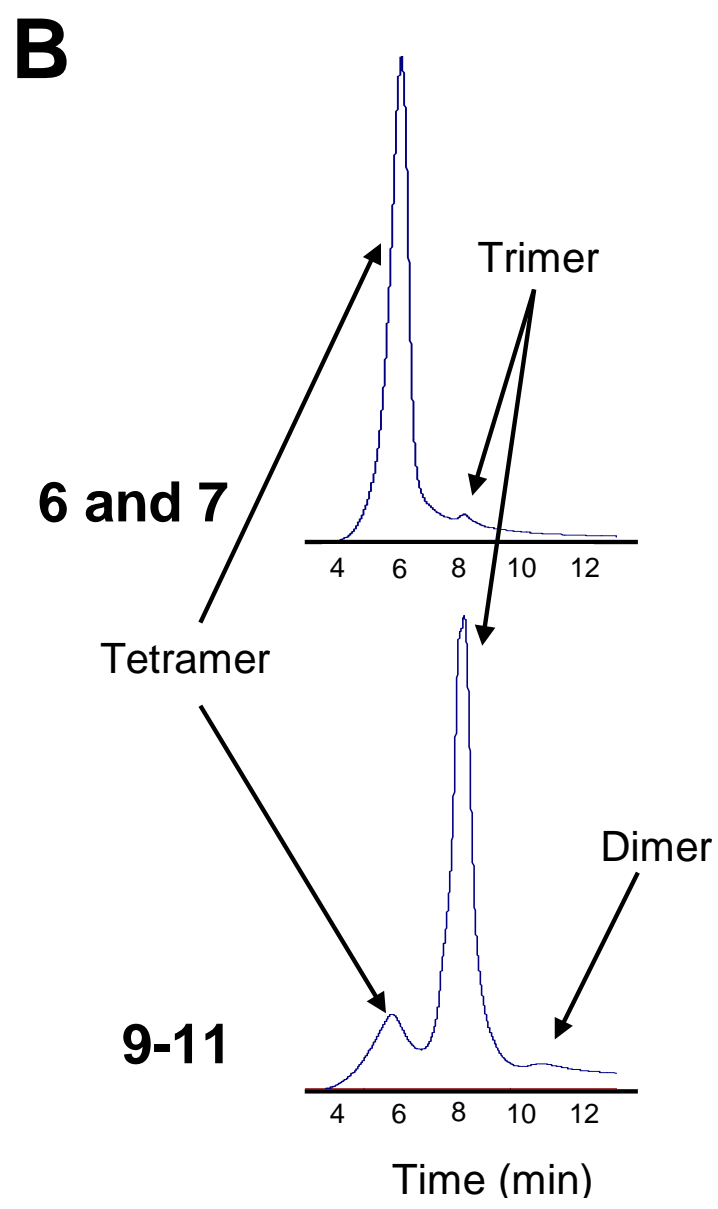

